\title{
Use of endoscopic distal attachment cap to enhance image stabilization in probe-based confocal laser endomicroscopy in colorectal lesions*
}

Authors

Institutions
Vivian Ussui ${ }^{1,}{ }^{*}$, Can $\mathrm{Xu}^{1,2,}{ }^{*}$, Julia E. Crook ${ }^{1}$, Nancy N. Diehl ${ }^{1}$, Joy Hardee ${ }^{1}$, Estela G. Staggs ${ }^{1}$, Muhammad W. Shahid $^{1}$, ${ }^{3}$, Michael B. Wallace ${ }^{1}$

${ }^{1}$ Mayo Clinic in Florida, Jacksonville, Florida, United States

${ }^{2}$ Department of Gastroenterology, Changhai Hospital, Second Military Medical University, Shanghai, China

${ }^{3}$ Owatonna Clinic, Mayo Clinic Health System, Owatonna, Minnesota, United States submitted

22. December 2014

accepted after revision

13. April 2015

\section{Bibliography}

DOI http://dx.doi.org/

10.1055/s-0034-1392233

Published online: 21.7 .2015

Endosc Int Open 2015; 03:

E516-E522

(c) Georg Thieme Verlag KG

Stuttgart · New York

E-ISSN 2196-9736

\section{Corresponding author:}

Michael B. Wallace, MD

Department of

Gastroenterology and

Hepatology

4500 San Pablo Road

Jacksonville, FL 32224

Fax: +1-904-953-7260

wallace.michael@mayo.edu
Background and study aims: Colorectal cancer can be prevented through the use of colonoscopy with polypectomy. Most colon polyps are benign or low grade adenomas. However, currently all lesions need histopathologic analysis, which increases diagnostic costs and delays the final diagnosis. Confocal laser endomicroscopy (CLE) is a new technology that enables real-time endomicroscopy. However, there are challenges to maintaining a stable image with currently available systems. We conducted a small study to obtain a preliminary assessment of whether the use of an endoscopic distal attachment cap may enhance image quality of CLE in comparison with images obtained with free-hand acquisition.

Patients and methods: Forty outpatients underwent colonoscopy for evaluation of colon polyps in a single academic medical center. Patients were assigned randomly to 1 of 2 study arms on

\section{Introduction}

Confocal laser endomicroscopy (CLE) has the potential to allow in vivo endomicroscopy and, thus, avoid the need to resect nonneoplastic polyps or to resect and discard small, low grade adenomas when a high-confidence, accurate diagnosis is made. Guidelines for this strategy have been outlined by the American Society for Gastrointestinal Endoscopy, among other resources [1]. Because of the extreme (1000-fold) magnification of both endoscopic confocal laser endomicroscopy (eCLE) and probe-based confocal laser endomicroscopy (pCLE) systems, maintaining a stable image is challenging.

The incidence of colorectal cancer (CRC) and CRCrelated deaths can be reduced by early detection with methods such as colonoscopy with polypec-

\footnotetext{
* This sudy was presented as a poster abstract at DDW 2013

** Drs. Ussui and Xu: These authors contributed equally.
}

the basis of whether an endoscopic distal attachment cap was used ( $n=21$, Cap Used) or not used ( $n=19$, No Cap) in the procedure. The quality of confocal images and probe stabilization was summarized.

Results: A total of 81 polyps were identified. The proportion of polyps with images of high quality was 74\% (28/38) in the Cap Used group and 79\% (30/38) in the No Cap arm. Image stability was also similar with and without a cap. Diagnostic accuracy was estimated to be slightly higher in the Cap Used group for probe-based confocal laser endomicroscopy (pCLE; 78\% vs 70\%). This was also true for white-light and narrow-band imaging.

Conclusions: This preliminary study did not yield any evidence to support that the use of an endoscopic distal attachment cap improves the quality of images obtained during CLE.

tomy [2]. Currently, more than one-third of resected polyps are nonneoplastic, and greater than $90 \%$ of neoplastic polyps are low grade tubular adenomas [3]. The cost of histopathologic confirmation of these is substantial, with more than 14 million colonoscopies performed annually in the United States [4]. Screening for CRC with colonoscopy is effective, safe, and widely used in the United States. Despite these advantages, the reliance on biopsy or polypectomy with ex vivo histopathologic examination remains a major limitation because of the increased risk to the patient associated with polypectomy of nonneoplastic lesions, overall cost, and delay in the final diagnosis.

In this study, we evaluated an image-enhancement technology, CLE, which enables in vivo histopathologic examination with mucosal analysis at the cellular level. This is particularly important for evaluating different types of polyps. Real-time assessment is possible through a high-resolution technique, which provides a 1000-fold magnifica- 


\begin{tabular}{|c|c|c|}
\hline & $\begin{array}{l}\text { No Cap } \\
(n=19)\end{array}$ & $\begin{array}{l}\text { Cap Used } \\
(\mathbf{n}=21)\end{array}$ \\
\hline Age at procedure, $y$ & $64(47,57,75,85)$ & $62(48,53,76,87)$ \\
\hline Sex, male, no. (\%) & $12(63)$ & $11(52)$ \\
\hline \multicolumn{3}{|l|}{ Race, no. (\%) } \\
\hline White & $16(84)$ & $18(86)$ \\
\hline African American & $2(11)$ & $1(5)$ \\
\hline Hispanic & $1(5)$ & $2(10)$ \\
\hline Patient history of CRC or adenoma, no. (\%) & $13(68)$ & $14(70)$ \\
\hline Family history of CRC, no. (\%) & $6(32)$ & $5(28)$ \\
\hline \multicolumn{3}{|l|}{ Indication for procedure, no. (\%) } \\
\hline Screening & $1(5)$ & $0(0)$ \\
\hline Surveillance average prior polyps & $1(5)$ & $2(10)$ \\
\hline EMR & $1(5)$ & $3(14)$ \\
\hline EMR follow-up & $14(74)$ & $15(71)$ \\
\hline Other (polypectomy, transanal resection, poor procedure preparation) & $2(11)$ & $1(5)$ \\
\hline
\end{tabular}

Table 1 Characteristics of $40 \mathrm{pa}-$ tients undergoing colonoscopy (January 10 - November 5, 2012) with or without an endoscopic distal attachment cap.

No Cap, colonoscopy performed without an endoscopic distal attachment cap; Cap Used, colonoscopy performed with an endoscopic distal attachment cap; CRC, colorectal cancer; EMR, endoscopic mucosal resection.

The sample median (minimum, $25^{\text {th }}$ percentile; maximum, $75^{\text {th }}$ percentile) is given for continuous variables. Information was unavailable for some patients regarding patient history of CRC or adenoma ( $n=1$, Cap Used) and family history of CRC ( $n=3$, Cap Used) and, therefore, could not been included in the summaries. Percentages for race in the Cap Used group sum to $101 \%$ because of rounding.

tion [5] and yields in vivo analysis of cellular components and vascular distribution. Two different types of CLE systems are currently available. One is integrated to the endoscope (eCLE) and developed by Pentax (Tokyo, Japan).The other is probe based (pCLE), which consists of a through-the-scope system from Mauna Kea Technologies (Paris, France) [6].

The primary aim of this study was to obtain a preliminary assessment of whether the use of an endoscopic distal attachment cap may enhance probe stabilization in comparison with free-hand image acquisition, with image quality as the primary outcome measure. Image quality was assessed by conducting an offline blinded review of images. Our secondary aims were to explore whether polyp size may be important in the comparison of image quality and probe stability. We also examined the confidence level and duration of, as well as compared images obtained with, pCLE, white-light (WL), and narrow-band (NB) imaging methods. Finally, we measured biopsy time, colonoscope insertion time, and colonoscope withdrawal time with or without the use of a cap.Comparison of confocal diagnosis was based on the Miami classification system [7] with regard to the histopathologic findings and distinction of neoplastic polyps between the 2 study groups.

\section{Patients/Materials and methods}

The study was approved by the Institutional Review Board of the Mayo Clinic (Jacksonville, Florida, USA) and was registered at clinicaltrials.gov (NCT01515514; Confocal Endomicroscopy for GI Neoplasia Study).

A total of 40 outpatients, who underwent planned colonoscopy (January 10 - November 5, 2012) for evaluation of colon polyps, were included in the study. Exclusion criteria were known polyposis syndromes, inflammatory bowel disease, allergy to fluorescein, or refusal to provide informed consent.

Just before the procedure was performed, each patient was assigned, through a computerized randomization system, to 1 of 2 study arms on the basis of whether an endoscopic distal attachment cap (4 mm, D-201-16403; Olympus America, Center Valley, Pennsylvania, USA) was used ( $\mathrm{n}=21$, Cap Used) or not used $(\mathrm{n}=$ 19 , No Cap). Standard colonoscopic imaging was performed first, followed by injection of $5 \mathrm{~mL}$ of $10 \%$ fluorescein (Akorn Pharmaceuticals, Lake Forest, Illinois, USA). One minute after fluorescein injection, pCLE imaging commenced and was continued until images of adequate quality, as defined by in-focus, stable imaging of colonic epithelium, were obtained from representative areas of the polyps. The probe was maintained 3 to $4 \mathrm{~mm}$ distal to the endoscope tip. When a cap was used, the cap was placed in direct contact with the colon wall and over the polyp to stabilize the image. Confocal imaging was subsequently performed. To standardize imaging relative to the fluorescein timing, no more than 3 lesions per patient were imaged, which was limited to the first 8 minutes after injection. All pCLE images were captured by the principal investigator of the study (M. B. W.), who has extensive experience with pCLE (>500 pCLE cases). The pCLE manipulation, including probe management and capture of images, was completed by either a research fellow, program coordinator, or visiting physician, all of whom had prior training. After imaging, each polyp was removed with snare or biopsy forceps and evaluated by using standard histopathologic methods.

Because the presence of a cap would not allow blinding during the study, all images on the Cellvizio system (Mauna Kea Technologies) video were recorded. Each video was reviewed offline by an expert (M. B. W.), who was blinded to the cap use and image acquisition method. Technical quality of each video sequence was scored subjectively by using the results of the histopathologic findings as a reference standard (1-5 scale: 1 , worst image quality; 3 , acceptable image quality; 5 , image quality equal to that of histopathologic findings). Scoring of image stability and motion artifact was also recorded by using a similar $1-5$ scale (1, worst image stability; 3 , acceptable image stability; 5 , stability equal to that of histopathologic findings).

Statistical considerations

- The study was designed as a preliminary and pilot study, with the aim of gaining estimates of accuracy of diagnosis, with the results intended to guide the design of a potentially larger and powered study. The study was not powered to definitively assess differences in the techniques. Thus, tests of statistical inference were not performed, because results can be misleading in small studies.

We planned to enroll 40 patients, with the expectation that colonoscopy in these patients would yield approximately 60 


\begin{tabular}{|c|c|c|}
\hline & $\begin{array}{l}\text { No Cap } \\
(n=41)\end{array}$ & $\begin{array}{l}\text { Cap Used } \\
(\mathrm{n}=40)\end{array}$ \\
\hline \multicolumn{3}{|l|}{ Image quality, no. (\%) } \\
\hline $1=$ worst & $0(0)$ & $0(0)$ \\
\hline 2 & $1(3)$ & $1(3)$ \\
\hline $3=$ acceptable & $7(18)$ & $9(24)$ \\
\hline 4 & $18(47)$ & $17(45)$ \\
\hline 5 = equal to histopathologic findings & $12(32)$ & $11(29)$ \\
\hline 4 or $5=$ high quality & $30(79)$ & $28(74)$ \\
\hline \multicolumn{3}{|l|}{ Image stability, no. (\%) } \\
\hline $1=$ worst & $2(5)$ & $4(10)$ \\
\hline 2 & $8(20)$ & $4(10)$ \\
\hline $3=$ acceptable & $7(18)$ & $14(35)$ \\
\hline 4 & $10(25)$ & $11(28)$ \\
\hline $5=$ equal to histopathologic findings & $13(33)$ & $7(18)$ \\
\hline 4 or $5=$ high quality & $23(58)$ & $18(45)$ \\
\hline Percent acceptable image & $70(10,43,90,95)$ & $60(10,50,70,95)$ \\
\hline \multicolumn{3}{|l|}{ Confidence level, no.(\%) } \\
\hline Low & $13(33)$ & $6(16)$ \\
\hline High & $27(68)$ & $32(84)$ \\
\hline \multicolumn{3}{|l|}{ Diagnosis, no. (\%) } \\
\hline Hyperplastic/normal tissue & $26(63)$ & $27(68)$ \\
\hline \multicolumn{3}{|l|}{ Adenoma } \\
\hline Low grade & $11(27)$ & $9(23)$ \\
\hline High grade & $1(2)$ & $4(10)$ \\
\hline Traditional serrated & $3(7)$ & $0(0)$ \\
\hline
\end{tabular}

No Cap, colonoscopy performed without an endoscopic distal attachment cap; Cap Used, colonoscopy performed with an endoscopic distal attachment cap.

The sample median (minimum, $25^{\text {th }}$ percentile; maximum, $75^{\text {th }}$ percentile) is given for percent acceptable image. Information for some polyps identified was unavailable regarding image quality ( $n=3$, No Cap; $n=2$, Cap Used), image stability ( $n=1$, No Cap), percent acceptable image ( $n=1$, No Cap), and confidence level ( $n=1$, No Cap; $n=2$, Cap Used) and, therefore, could not been included in the summaries.

Percentage sums that do not equal $100 \%$ are due to rounding.

\begin{tabular}{|c|c|c|c|}
\hline & $\begin{array}{l}\text { Overall polyps identified } \\
(\mathrm{N}=81)\end{array}$ & $\begin{array}{l}\text { No Cap } \\
(n=41)\end{array}$ & $\begin{array}{l}\text { Cap Used } \\
(\mathrm{n}=40)\end{array}$ \\
\hline \multicolumn{4}{|l|}{ Polyp size, mm, no.(\%) } \\
\hline $1-4$ & $22(27)$ & $13(32)$ & $9(23)$ \\
\hline $5-8$ & $16(20)$ & $9(22)$ & $7(18)$ \\
\hline 10 & $14(17)$ & $9(22)$ & $5(13)$ \\
\hline$\geq 15$ & $13(16)$ & $3(7)$ & $10(25)$ \\
\hline No size recorded & $16(20)$ & $7(17)$ & $9(23)$ \\
\hline $1-9$ & $38(47)$ & $22(54)$ & $16(40)$ \\
\hline$\geq 10$ & $27(33)$ & $12(29)$ & $15(38)$ \\
\hline No size recorded & $16(20)$ & $7(17)$ & $9(23)$ \\
\hline Prior EMR site, no. (\%) & $24(30)$ & $13(32)$ & $11(28)$ \\
\hline \multicolumn{4}{|l|}{ Site, no. (\%) } \\
\hline Cecum & $14(17)$ & $8(20)$ & $6(15)$ \\
\hline Ascending colon & $20(25)$ & $8(20)$ & $12(30)$ \\
\hline Hepatic flexure & $2(2)$ & $1(2)$ & $1(3)$ \\
\hline Transverse colon & $11(14)$ & $7(17)$ & $4(10)$ \\
\hline Splenic flexure & $1(1)$ & $0(0)$ & $1(3)$ \\
\hline Descending colon & $3(4)$ & $1(2)$ & $2(5)$ \\
\hline Sigmoid colon & $13(16)$ & $8(20)$ & $5(13)$ \\
\hline Rectum & $17(21)$ & $8(20)$ & $9(23)$ \\
\hline \multicolumn{4}{|l|}{ Histopathologic findings, no. (\%) } \\
\hline Hyperplastic tissue & $17(22)$ & $10(27)$ & $7(18)$ \\
\hline Other non-neoplasia & $27(35)$ & $10(27)$ & $17(43)$ \\
\hline Adenoma & $27(35)$ & $16(43)$ & $11(28)$ \\
\hline Traditional serrated adenoma & $3(4)$ & $1(3)$ & $2(5)$ \\
\hline Tubulovillous adenoma & $3(4)$ & $0(0)$ & $3(8)$ \\
\hline
\end{tabular}

No Cap, colonoscopy performed without an endoscopic distal attachment cap; Cap Used, colonoscopy performed with an endoscopic distal attachment cap; EMR, endoscopic mucosal resection.

Information was unavailable for some polyps identified regarding histopathologic findings ( $n=4$, No Cap) and, therefore, could not been included in the summaries. No polyps were $9 \mathrm{~mm}$. No polyps were in the range of 11 to $14 \mathrm{~mm}$. Percentage sums that do not equal $100 \%$ are due to rounding.

Table 2 Offline probe-based confocal laser endomicroscopy (pCLE) image interpretation of 81 polyps resected from 40 patients undergoing colonoscopy (January 10 - November 5, 2012) with or without an endoscopic distal attachment cap.

Characteristics of 81 polyps resected from 40 patients undergoing colonoscopy (January 10 - November 5, 2012) with or without an endoscopic distal attachment cap. 
Table 4 Diagnostic accuracy, with the use of white-light (WL), narrow-band (NB), and probe-based confocal laser endomicroscopy ( $\mathrm{PCLE}$ ) offline and online imaging methods, for 81 (77 evaluable) polyps resected from 40 patients undergoing colonoscopy (January 10 - November 5, 2012) with or without an endoscopic distal attachment cap.

\begin{tabular}{|c|c|c|c|c|c|c|}
\hline \multirow[t]{2}{*}{ Imaging diagnosis } & \multicolumn{3}{|l|}{ No Cap } & \multicolumn{3}{|l|}{ Cap Used } \\
\hline & $\begin{array}{l}\text { Normal tissue } \\
(n=20)\end{array}$ & $\begin{array}{l}\text { Adenoma } \\
(n=17)\end{array}$ & $\begin{array}{l}\text { Accuracy, no. (\%) } \\
(n=37)\end{array}$ & $\begin{array}{l}\text { Normal tissue } \\
(n=24)\end{array}$ & $\begin{array}{l}\text { Adenoma } \\
(n=16)\end{array}$ & $\begin{array}{l}\text { Accuracy, no. (\%) } \\
(n=40)\end{array}$ \\
\hline WL & & & $26 / 37(70)$ & & & $32 / 39(82)$ \\
\hline Hyperplastic/normal tissue & 14 & 5 & & 18 & 2 & \\
\hline \multicolumn{7}{|l|}{ Adenoma } \\
\hline Low grade & 5 & 8 & & 3 & 4 & \\
\hline High grade & 0 & 3 & & 0 & 7 & \\
\hline Traditional serrated & 1 & 1 & & 2 & 3 & \\
\hline NB & & & $27 / 36(75)$ & & & $33 / 39(85)$ \\
\hline Hyperplastic/normal tissue & 13 & 2 & & 18 & 1 & \\
\hline \multicolumn{7}{|l|}{ Adenoma } \\
\hline Low grade & 6 & 10 & & 3 & 5 & \\
\hline High grade & 0 & 4 & & 0 & 7 & \\
\hline Traditional serrated & 1 & 0 & & 2 & 3 & \\
\hline pCLE offline & & & $26 / 37(70)$ & & & $31 / 40(78)$ \\
\hline Hyperplastic/normal tissue & 16 & 7 & & 21 & 6 & \\
\hline \multicolumn{7}{|l|}{ Adenoma } \\
\hline Low grade & 2 & 8 & & 3 & 6 & \\
\hline High grade & 0 & 1 & & 0 & 4 & \\
\hline Traditional serrated & 2 & 1 & & 0 & 0 & \\
\hline pCLE online & & & $26 / 37(70)$ & & & $32 / 40(80)$ \\
\hline Hyperplastic/normal tissue & 15 & 6 & & 21 & 5 & \\
\hline \multicolumn{7}{|l|}{ Adenoma } \\
\hline Low grade & 1 & 8 & & 2 & 4 & \\
\hline High grade & 2 & 2 & & 0 & 7 & \\
\hline Traditional serrated & 2 & 1 & & 1 & 0 & \\
\hline
\end{tabular}

No Cap, colonoscopy performed without an endoscopic distal attachment cap; Cap Used, colonoscopy performed with an endoscopic distal attachment cap. Some information was unavailable regarding WL imaging diagnosis ( $n=1$, No Cap; $n=1$, Cap Used) and NB imaging diagnosis ( $n=2$, No Cap; $n=1$, Cap Used) and, therefore, could not been included in the summaries. Accuracy refers to presumed diagnosis of adenoma versus hyperplastic/normal tissue.

discovered polyps in total, on the basis on many prior trials involving colon polyps. For the comparison of groups (Cap Used vs No Cap), we expected around 60 polyps. Because the focus of this study was to gain a preliminary assessment of the potential utility of the use of a cap to guide future research, the analysis consisted of descriptive summaries only. Our primary summary measure was the proportion with a high score for the purpose of imaging quality. A score of either 4 or 5 was designated as a high score.

\section{Results}

Patient characteristics, including age, sex, race, patient history of CRC or adenoma, family history of CRC, and indication for procedure, were distributed similarly across the 2 study groups ( $\bullet$ Table 1).

For all 81 polyps identified, image quality and stability were similar between the 2 study groups. In specific, the proportion of images with a high quality score (4 or 5 ) was $74 \%(28 / 38)$ in the Cap Used group versus 79\% (30/38) in the No Cap arm. We also observed that the use of the cap yielded a slightly lower proportion of images with high image stability score $(45 \% ; 18 / 40)$ in comparison with images collected without the cap $(58 \% ; 23 / 40)$ ( $\bullet$ Table 2). Higher confidence levels were also observed in the Cap Used group, with $84 \%$ (32/38) versus 68\% (27/40) in the No Cap group ( Table 2 ).
Both insertion and withdrawal times were faster with a cap than without a cap (data not shown). The number of polyps found was similar ( $n=40$, Cap Used group; $n=41$, No Cap group) ( $\bullet$ Table 2 and Table 3). Among polyp characteristics, the proportion of lesions that were neoplastic (including adenoma or traditional serrated adenoma) in the No Cap and Cap Used groups was $46 \%$ and $40 \%$, respectively ( $\bullet$ Table 2 ).

When comparing diagnostic accuracy (adenoma vs non-adenoma) among different imaging methods (WL, NB, and pCLE offline and online), we found that the Cap Used group had slightly higher diagnostic accuracy estimates than were observed for the No Cap group for all imaging modalities ( $\bullet$ Table 4 ).

In both groups, overall image quality was better for lesions measuring $10 \mathrm{~mm}$ or greater, in comparison with lesions measuring between 1 and $9 \mathrm{~mm}$ (70\% and $60 \%$ of acceptable images, respectively). The imaging quality and image stability were similar with and without a cap ( $\bullet$ Table 5 and $\bullet$ Table 6 ).

When assessing correspondence between the confocal Miami criteria and the histopathologic diagnosis, we found a stronger association with thickness, darkness, and vessels in the Cap Used group, but no association with the presence/absence of goblet cells ( Table 7).

\section{Discussion}

$\nabla$

Overall, this preliminary study did not yield sufficient evidence to support that the use of a cap improves the quality or stability 


\begin{tabular}{|c|c|c|c|}
\hline & $\begin{array}{l}\text { Overall polyps } \\
\text { identified } \\
(\mathrm{N}=38)\end{array}$ & $\begin{array}{l}\text { No Cap } \\
(n=22)\end{array}$ & $\begin{array}{l}\text { Cap Used } \\
(n=16)\end{array}$ \\
\hline \multicolumn{4}{|l|}{ Image quality, no.(\%) } \\
\hline $1=$ worst & $0(0)$ & $0(0)$ & $0(0)$ \\
\hline 2 & $1(3)$ & $1(5)$ & $0(0)$ \\
\hline $3=$ acceptable & $8(23)$ & $5(25)$ & $3(20)$ \\
\hline 4 & $19(54)$ & $10(50)$ & $9(60)$ \\
\hline $5=$ equal to histopathologic findings & $7(20)$ & $4(20)$ & $3(20)$ \\
\hline Mean (SD) & $3.9(0.7)$ & $3.9(0.8)$ & $4.0(0.7)$ \\
\hline \multicolumn{4}{|l|}{ Image stability, no.(\%) } \\
\hline $1=$ worst & $3(8)$ & $2(9)$ & $1(6)$ \\
\hline 2 & $7(18)$ & $4(18)$ & $3(19)$ \\
\hline $3=$ acceptable & $11(29)$ & $5(23)$ & $6(38)$ \\
\hline 4 & $10(26)$ & $6(27)$ & $4(25)$ \\
\hline $5=$ equal to histopathologic findings & $7(18)$ & $5(23)$ & $2(13)$ \\
\hline Mean (SD) & $3.3(1.2)$ & $3.4(1.3)$ & $3.2(1.1)$ \\
\hline Percent acceptable image & $60(10,40,70,95)$ & $65(10,40,80,95)$ & $55(15,40,70,95)$ \\
\hline \multicolumn{4}{|l|}{ Confidence level, no.(\%) } \\
\hline Low & $9(24)$ & $8(36)$ & $1(6)$ \\
\hline High & $29(76)$ & $14(64)$ & $15(94)$ \\
\hline \multicolumn{4}{|l|}{ Diagnosis, no. (\%) } \\
\hline Hyperplastic/normal tissue & $29(76)$ & $16(73)$ & $13(81)$ \\
\hline \multicolumn{4}{|l|}{ Adenoma } \\
\hline Low grade & $8(21)$ & $5(23)$ & $3(19)$ \\
\hline High grade & $1(3)$ & $1(5)$ & $0(0)$ \\
\hline Traditional serrated & $0(0)$ & $0(0)$ & $0(0)$ \\
\hline
\end{tabular}

Table 5 Offline probe-based confocal laser endomicroscopy (pCLE) image interpretation of 38 polyps, measuring between 1 and $9 \mathrm{~mm}$, resected from 40 patients undergoing colonoscopy (January 10 - November 5,2012 ) with or without an endoscopic distal attachment cap.

SD, standard deviation.

The sample median (minimum, $25^{\text {th }}$ percentile; maximum, $75^{\text {th }}$ percentile) is given for percent acceptable image. Information for some polyps identified was unavailable regarding image quality ( $n=2$, No Cap; $n=1$, Cap Used). Percentage sums that do not equal $100 \%$ are due to rounding.

\begin{tabular}{|c|c|c|c|}
\hline & $\begin{array}{l}\text { Overall polyps identified } \\
(\mathrm{N}=27)\end{array}$ & $\begin{array}{l}\text { No Cap } \\
(n=12)\end{array}$ & $\begin{array}{l}\text { Cap Used } \\
(\mathbf{n}=15)\end{array}$ \\
\hline \multicolumn{4}{|l|}{ Image quality, no. (\%) } \\
\hline $1=$ worst & $0(0)$ & $0(0)$ & $0(0)$ \\
\hline 2 & $1(4)$ & $0(0)$ & $1(7)$ \\
\hline $3=$ acceptable & $8(31)$ & $2(17)$ & $6(43)$ \\
\hline 4 & $8(31)$ & $4(33)$ & $4(29)$ \\
\hline $5=$ equal to histopathologic findings & $9(35)$ & $6(50)$ & $3(21)$ \\
\hline Mean (SD) & $4.0(0.9)$ & $4.3(0.8)$ & $3.6(0.9)$ \\
\hline \multicolumn{4}{|l|}{ Image stability, no.(\%) } \\
\hline $1=$ worst & $3(11)$ & $0(0)$ & $3(20)$ \\
\hline 2 & $4(15)$ & $3(25)$ & $1(7)$ \\
\hline $3=$ acceptable & $6(22)$ & $1(8)$ & $5(33)$ \\
\hline 4 & $8(30)$ & $3(25)$ & $5(33)$ \\
\hline $5=$ equal to histopathologic findings & $6(22)$ & $5(42)$ & $1(7)$ \\
\hline Mean (SD) & $3.4(1.3)$ & $3.8(1.3)$ & $3.0(1.3)$ \\
\hline Percent acceptable image & $70(10,40,80,95)$ & $75(25,45,90,95)$ & $50(10,30,70,95)$ \\
\hline \multicolumn{4}{|l|}{ Confidence level, no. (\%) } \\
\hline Low & $9(35)$ & $4(33)$ & $5(36)$ \\
\hline High & $17(65)$ & $8(67)$ & $9(64)$ \\
\hline \multicolumn{4}{|l|}{ Diagnosis, no. (\%) } \\
\hline Hyperplastic/normal tissue & $10(37)$ & $4(33)$ & $6(40)$ \\
\hline \multicolumn{4}{|l|}{ Adenoma } \\
\hline Low grade & $11(41)$ & $6(50)$ & $5(33)$ \\
\hline High grade & $4(15)$ & $0(0)$ & $4(27)$ \\
\hline Traditional serrated & $2(7)$ & $2(17)$ & $0(0)$ \\
\hline
\end{tabular}

Table 6 Offline probe-based confocal laser endomicroscopy ( $\mathrm{pCLE}$ ) image interpretation of 27 polyps, measuring $10 \mathrm{~mm}$ or greater, resected from 40 patients undergoing colonoscopy (January 10 - November 5, 2012) with or without an endoscopic distal attachment cap.

SD, standard deviation.

The sample median (minimum, $25^{\text {th }}$ percentile; maximum, $75^{\text {th }}$ percentile) is given for percent acceptable image. Information for some polyps identified was unavailable regarding image quality ( $n=1$, Cap Used) and confidence level ( $n=1$, Cap Used). Percentage sums that do not equal $100 \%$ are due to rounding. 
Table 7 Correspondence of Miami classification system ${ }^{1}$ with histopathologic findings for 81 (77 evaluable for Miami classification) polyps resected from 40 patients undergoing colonoscopy (January 10 - November 5, 2012) with or without an endoscopic distal attachment cap.

\begin{tabular}{|c|c|c|c|c|c|c|}
\hline & \multicolumn{3}{|l|}{ No Cap } & \multicolumn{3}{|l|}{ Cap Used } \\
\hline & $\begin{array}{l}\text { Normal tissue } \\
(n=20)\end{array}$ & $\begin{array}{l}\text { Adenoma } \\
(n=17)\end{array}$ & $\begin{array}{l}\text { Correspondence, no. (\%) } \\
(n=37)\end{array}$ & $\begin{array}{l}\text { Normal tissue } \\
(n=24)\end{array}$ & $\begin{array}{l}\text { Adenoma } \\
(n=16)\end{array}$ & $\begin{array}{l}\text { Correspondence, no. (\%) } \\
(n=40)\end{array}$ \\
\hline Crypt class & & & $\mathrm{n} / \mathrm{a}$ & & & $\mathrm{n} / \mathrm{a}$ \\
\hline Round & 5 & 1 & & 6 & 0 & \\
\hline Stellate & 11 & 5 & & 14 & 4 & \\
\hline Irregular or villiform & 2 & 10 & & 3 & 10 & \\
\hline Disorganized & 1 & 0 & & 0 & 1 & \\
\hline Goblet cells & & & $12 / 37(32)$ & & & $10 / 40(25)$ \\
\hline Absent & 3 & 8 & & 4 & 10 & \\
\hline Present & 17 & 9 & & 20 & 6 & \\
\hline Epithelial thickness & & & $27 / 37(73)$ & & & $33 / 40(83)$ \\
\hline Uniform/thin & 17 & 7 & & 22 & 5 & \\
\hline Irregular/thick & 3 & 10 & & 2 & 11 & \\
\hline Epithelial darkness & & & $27 / 37(73)$ & & & $33 / 40(83)$ \\
\hline Not dark & 17 & 7 & & 22 & 5 & \\
\hline Dark & 3 & 10 & & 2 & 11 & \\
\hline Vessels & & & $26 / 36(72)$ & & & $32 / 40(80)$ \\
\hline Thin & 16 & 7 & & 22 & 6 & \\
\hline Dilated/irregular & 3 & 10 & & 2 & 10 & \\
\hline
\end{tabular}

n/a, nonapplicable.

Information for some polyps identified was unavailable regarding crypt class ( $n=2$, No Cap; $n=2$, Cap Used) and vessels ( $n=1$, No Cap).

${ }^{1}$ Wallace M, Lauwers GY, Chen Y et al. Miami classification for probe-based confocal laser endomicroscopy. Endoscopy 2011; 43 : 882 - 891

of pCLE images. This does not mean that it is not effective, and this trial is still a pilot study that was not powered to assess for statistical difference. However, a much larger, well-powered study may identify that image quality is improved with use of a cap.

Although promising, in vivo polyp-discrimination methods have not been widely endorsed. Methods that require mucosal staining have proved to be cumbersome for screening examinations. In addition, zoom (magnifying) endoscopes can be fragile and expensive, and regional differences in magnification offered by available video processors have limited the reproducibility of NB imaging-discrimination methods outside of Japan and the United Kingdom [8]. Although results of 1 small western study seem to support that mesh capillary vessel presence can be accurately assessed without the need for an optical magnification processor [9], differences in the processors' diagnostic ability have also been described [10]. Citing the limitations of electronic magnification in visual discrimination, Rex et al [10] introduced the concept of applying confidence levels to endoscopic prediction in the hope of improving predictive accuracy. Predictions of polyp histopathologic findings were made with high confidence $81 \%$ and $92 \%$ of the time for diminutive hyperplastic and adenomatous polyps, respectively. From this group, high levels of predictive accuracy were shown for both hyperplastic (95\%) and adenomatous (91\%) lesions [10]. Despite showing that mucosal patterns are highly accurate in predicting neoplasia, the lower than ideal confidence in predicting hyperplastic lesions (81\%) means that a large number of lesions would still require polypectomy.

Our group has evaluated advanced endoscopic imaging methods and PCLE for polyp discrimination. In a large, single-blind trial, pCLE was found to be superior to current state-of-the-art, NB or Fuji Intelligent Chromo Endoscopy (FICE), imaging. However, in neither method were critical thresholds needed to avoid the need for histopathologic evaluation reached [11].Furthermore,
pCLE is a cumbersome process that requires exogenous fluorescein dye and expensive confocal probes.

As with all endoscopic imaging methods, pCLE relies on the ability of the operator to acquire images of high quality and interpret them with reliability and accuracy $[6,11]$. Although pCLE offers greater convenience and compatibility with all standard endoscopes, the free-hand nature of holding the pCLE in contact with tissue presents challenges to gaining stable, high quality images [12]. Few studies with options to improve image stability have been published to date. The eCLE systems overcome this by applying suction to the tip of the endoscopes, which is integrated with the CLE imaging window [13]. A hand-held instrument with the purpose of providing contact force and better confocal images has been developed that may overcome natural bowel movements and also the subjective motion from the hand of the operator [14].

Our group previously published a study comparing the accuracy of standard imaging and pCLE for colorectal polyps. We have generally observed that pCLE has a lower diagnostic accuracy for imaging small polyps and speculate that this is due to difficulties in maintaining good probe contact and image stability [15].

A limitation of the current study is that it was performed in a single center that has substantial experience in PCLE. This experience may reduce the differences between different techniques (Cap Used vs No Cap) because we have a significant amount of experience with the free-hand methods. The study was also limited by small sample size and could only provide preliminary comparisons.

In summary, our study findings do not support that the use of a cap improves image stability, although it may increase the accuracy of pCLE and other imaging methods for small polyps. There is still need for larger randomized trials with different image stabilization techniques or devices when using pCLE technology. 
Competing interests: Dr. Wallace receives research funding from Olympus, NinePoint Medical, and Cosmo Pharmaceuticals.

\section{Acknowledgements}

Grant support from Mayo Clinic Foundation for Research and Education

\section{References}

1 Rex DK, Kahi C, O'Brien M et al. The American Society for Gastrointestinal Endoscopy PIVI (Preservation and Incorporation of Valuable Endoscopic Innovations) on real-time endoscopic assessment of the histology of diminutive colorectal polyps. Gastrointest Endosc 2011; 73: $419-422$

2 Levin B, Lieberman DA, McFarland B et al. Screening and surveillance for the early detection of colorectal cancer and adenomatous polyps, 2008: a joint guideline from the American Cancer Society, the US Multi-Society Task Force on Colorectal Cancer, and the American College of Radiology. Gastroenterology 2008; 134: 1570-1595

3 Odom SR, Duffy SD, Barone JE et al. The rate of adenocarcinoma in endoscopically removed colorectal polyps. Am Surg 2005; 71: 10241026

4 Seeff $L C$, Richards TB, Shapiro JA et al. How many endoscopies are performed for colorectal cancer screening? Results from CDC's survey of endoscopic capacity. Gastroenterology 2004; 127: 1670-1677

5 Wallace MB, Kiesslich R. Advances in endoscopic imaging of colorectal neoplasia. Gastroenterology 2010; 138: 2140 - 2150

6 Ussui VM, Wallace MB. Confocal endomicroscopy of colorectal polyps. Gastroenterol Res Pract 2012: DOI 10.1155/2012/545679
7 Wallace M, Lauwers GY, Chen $Y$ et al. Miami classification for probebased confocal laser endomicroscopy. Endoscopy 2011; 43: 882-891

8 Parra-Blanco A, Matsuda T, Fujii T et al. Diagnostic advantage of optical vs electronic magnification for the diagnosis of colonic polyps. Gastrointest Endosc 2008: AB126. 67: http://www.giejournal.org/article/ S0016-5107(08)00626-3/abstract

9 Wang AY, Shami VM, Kahaleh $M$ et al. Presence of meshed capillary vessels on narrow-band imaging effectively identifies colorectal neoplasia without optical magnification: a North American validation of the Japanese experience. Gastrointest Endosc 2009; 69: AB297. http:// www.giejournal.org/article/S0016-5107(09)01312-1/abstract

10 Rex DK. Narrow-band imaging without optical magnification for histologic analysis of colorectal polyps. Gastroenterology 2009; 136: $1174-$ 1181

11 Buchner AM, Shahid MW, Heckman MG et al. Comparison of probebased confocal laser endomicroscopy with virtual chromoendoscopy for classification of colon polyps. Gastroenterology 2010; 138: $834-$ 842

12 Wells AP, Wakely L, Birchall $W$ et al. In vivo fibreoptic confocal imaging (FOCI) of the human ocular surface. J Anat 2006; 208: 197-203

13 Kiesslich R, Burg J, Vieth $M$ et al. Confocal laser endoscopy for diagnosing intraepithelial neoplasias and colorectal cancer in vivo. Gastroenterology 2004; 127: 706-713

14 Latt WT, Newton RC, Visentini-Scarzanella $M$ et al. A hand-held instrument to maintain steady tissue contact during probe-based confocal laser endomicroscopy. IEEE Trans Biomed Eng 2011; 58: 2694 - 2703

15 Shahid MW, Buchner AM, Raimondo $M$ et al. Accuracy of real-time vs. blinded offline diagnosis of neoplastic colorectal polyps using probebased confocal laser endomicroscopy: a pilot study. Endoscopy 2012; 44: $343-348$ 